\title{
Identification and prevalence of ectoparasites in cattle and sheep in and around Bishoftu town, central Ethiopia
}

\author{
Meseret Gebreselama ${ }^{1}$, Fikre Zeru ${ }^{2}$, Gebremedhin Romha ${ }^{3, *}$ \\ ${ }^{1}$ Elfora Agro-industries export abattoir, Bishoftu, P. O. Box 2500, Bishoftu, Ethiopia \\ ${ }^{2}$ College of Veterinary Medicine, Samara University, P.O. Box 132, Samara, Ethiopia \\ ${ }^{3}$ Dilla University, College of Agriculture and Natural Resource, Department of Animal and Range Science, P.O. Box 419, Dilla, Ethiopia
}

\section{Email address:}

mesif12@yahoo.com (M. Gebreselama), fikrem24@yahoo.com (F. Zeru), gebremedhinromha@yahoo.com (G. Romha)

\section{To cite this article:}

Meseret Gebreselama, Fikre Zeru, Gebremedhin Romha. Identification and Prevalence of Ectoparasites in Cattle and Sheep in and Around Bishoftu Town, Central Ethiopia. Animal and Veterinary Sciences. Vol. 2, No. 4, 2014, pp. 124-129.

doi: 10.11648/j.avs.20140204.17

\begin{abstract}
A cross-sectional study was conducted from October, 2010 to May, 2011 on a total of 384 cattle and sheep to identify the major ectoparasites and to determine their prevalence in and around Bishoftu town, central Ethiopia. Out of 202 cattle and 182 sheep examined for ectoparasites, 95 (47.0\%) cattle and 73 (40.1\%) sheep were found to be infested with one or more ectoparasites. Overall eight genera of ectoparasites belonging to ticks (Boophilus, Amblyomma, Rhepicephalus and Hyalomma), lice (Damalina and Linognathus) and mange mite (Demodex spp and Psoroptes spp) were encountered in the study area. Prevalence of tick infestation was 35.2\% (71/202) in cattle and $26.9 \%(49 / 182)$ in sheep. Among the risk factors assessed, female animals (cattle: $\chi 2=5.4, \mathrm{P}=0.020$; sheep: $\chi 2=5.5, \mathrm{P}=0.019)$ and production system (cattle: $\chi 2=29.4$, $\mathrm{P}=0.000$; sheep: $\chi 2=10.3, \mathrm{P}=0.001)$ were significantly associated with prevalence of tick infestation. The prevalence of pediculosis was $8.9 \%$ and $12.6 \%$ in bovine and ovine, respectively. Sex $(\chi 2=19.3 ; \mathrm{P}=0.000)$ and breed $(\chi 2=4.6 ; \mathrm{P}=0.033)$ in cattle, and production system in both cattle $(\chi 2=5.5 ; \mathrm{P}=0.020)$ and sheep $(\chi 2=6.4 ; \mathrm{P}=0.040)$ were found to be significantly associated with the prevalence of pediculosis. The prevalence of demodicosis and psoroptic mange in cattle was $6.6 \%$ and $0.6 \%$, respectively. However, the only mange mite species encountered in sheep was Psoroptes with the prevalence rate of $2.2 \%$. Age in cattle $(\chi 2=14.0 ; \mathrm{P}=0.000)$ and sheep $(\chi 2=3.8 ; \mathrm{P}=0.040)$, and body condition in cattle $(\chi 2=7.7 ; \mathrm{P}=0.021)$ were found to be significantly associated with the prevalence of mange mite infestation. The present study revealed that widespread occurrence of ectoparasites in cattle and sheep in the study area, and the major ectoparasites identified were tick, lice and mange mite, thus, improved management practice and well-coordinated control interventions are required.
\end{abstract}

Keywords: Tick Infestation, Pediculosis, Mange Mite, Risk Factors, Bishoftu, Ethiopia

\section{Introduction}

Livestock serve as an important source of income for the agrarian community and are one of the Ethiopia's major sources of foreign currency through exportation of skins and hides [1]. However, diseases have been the stumbling block against the full utilization of this resource for foreign currency through export of live animals, skin and hides $[1,2]$. Different causes of skin disease are accountable for considerable economic loss particularly to the skin and hide export due to various defects, $65 \%$ of which occur in the pre-slaughter slaves directly related mostly to skin disease causing often rejection because of poor quality [3-5].

Ectoparasites are ubiquitous, often highly damaging and in most cases cannot be permanently eradicated, as a result ectoparasitism represents a major obstacle to development and utilization of animal resource [6,7], and causes huge livestock production losses [8-11). Ectoparasites in ruminants cause serious economic loss to small holder farmers and the tanning industry through mortality of animals, decreased production, down grading and rejection of skin and hide [12-16]. Moreover, they are the most important vectors of protozoan, bacterial, viral and rickettsial diseases [17]. Ectoparasitic diseases such as sarcoptic and psoroptic mange, tick and lice infestation have frequently been reported in Ethiopia [5,18-20] and these are among the threats that resulting in serious economic loss to the tanning industry and the country as a whole [21]. 
However, in this study area identification and distribution of ectoparasites in cattle and sheep has not been yet conducted despite the information regarding the ectoparasites is helpful in deploying integrated approaches and or alternative control methods. Therefore, the aim of this study was to, determine the distribution and identify the major ectoparasites prevailing in the area.

\section{Materials and Methods}

\subsection{Study Area and Animals}

The study was conducted in and around Bishoftu town, central Ethiopia. It is located $45 \mathrm{~km}$ south east of Addis Ababa. It lies $9^{0} \mathrm{~N}$ latitude and $40^{\circ} \mathrm{E}$ longitude at an altitude of $1950 \mathrm{~m}$ above sea level. The rainfall is bimodal. It receives an annual rainfall of $1151.6 \mathrm{~mm}$ of which $84 \%$ is received during the long rainy season covering June to September and the remaining in the short rainy season extending from March to May. The mean maximum and minimum temperature of the area is $34.7^{\circ} \mathrm{C}$ and $8.5^{\circ} \mathrm{C}$ respectively, and mean relative humidity is $61.3 \%$ [22]. The study animals used in this study were diseased (any disease) cattle and sheep admitted to the school of veterinary medicine clinic, Addis Ababa University, Bishoftu, Ethiopia.

\subsection{Study Design}

A cross-sectional study was conducted from October, 2010 to May, 2011 on 384 cattle and sheep to identify the major ectoparasites (to genus level) prevailing in the study area and to determine their prevalence.

\subsection{Sampling Method and Sample Size Determination}

Animals presented to the School of Veterinary Medicine clinic for any disease were subjected to detail examination for the presence of ectoparasites. Animals those admitted to the clinic were selected using a simple random sampling method, and the sample size required was obtained using the formula given by Thrusfield [23]. The age of the animals was estimated using the definition described by Aiello and Mays [24]. Animals were divided into two groups, namely young ( $\leq 1$ year old) and adult animals $(>1$ year old). Body condition score was made by the scoring system described by Nicholson and Butterworth [25] and Gatenby [26] in cattle and sheep, respectively. As previous study has not been conducted on ectoparasites in the study area, the expected prevalence was assumed to be $50 \%$. Therefore, the sample size calculated at $50 \%$ prevalence rate with a desired precision of $5 \%$ and $95 \%$ confidence interval.

\subsection{Collection and Identification of Ectoparasites}

After the animal was restrained physically, clinical examination for ectoparasites was performed by visual inspection and palpation of skin for parasites and/or lesions on all parts of the animal. Ectoparasites encountered either on the skin surface or attached to the hair were sampled and were collected in $70 \%$ ethanol alcohol labeled with serial numbers while other data such as age, sex of animals and production system were written on special field registration format prepared for this study. Skin scrapping from suspected cases of mange were collected and preserved in $10 \%$ formalin. After addition of $10 \% \mathrm{KOH}$ to the specimen, mites may be released from scabs and crusts before examination following the procedure indicated by Soulsby [27]. The collected ectoparasites were identified to genus level at the parasitology laboratory of the School of Veterinary Medicine, Addis Ababa University under stereomicroscope as per the procedure recommended by Urquhart et al. [28].

\subsection{Data Analysis}

The collected data were entered into Microsoft Excel data sheets and analyzed using STATA 11 statistical software (STATA Corporation, College Station, TX). The prevalence was calculated by dividing the proportion of animals found infested by the total number of animals inspected for external parasite multiplied by 100. The association between the effects of different risk factors and prevalence was analyzed using the Pearson chi-square $\left(\chi^{2}\right)$ test. The odds ratio (OR) was calculated to assess the strength of association of different risk factors with the prevalence of ectoparasites. A statistically significant association between variables was said to exist if the calculated P-value was $<0.05$ and the $95 \%$ confidence interval (CI) for OR doesn't include 1.

\section{Results}

\subsection{Overall Prevalence of Ectoparasites}

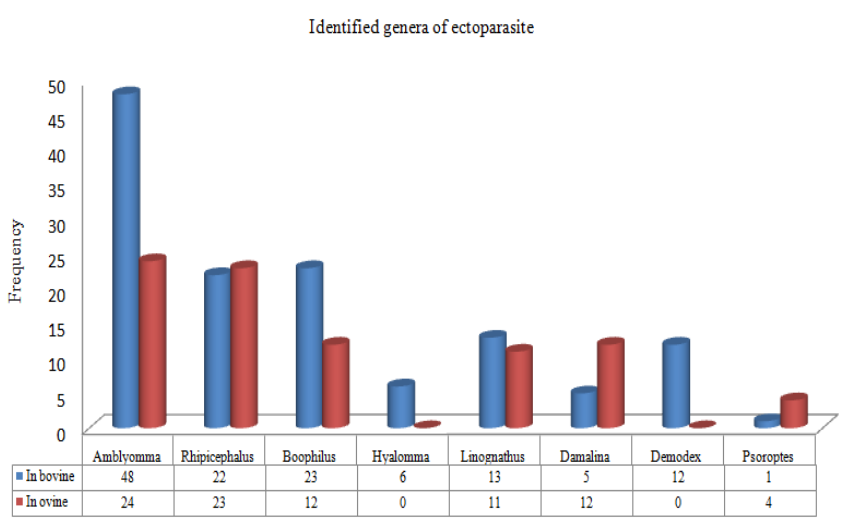

Figure 1. Identified genera of ectoparasites in cattle and sheep examined in and around Bishoftu town, Ethiopia

Overall eight genera of ectoparasites (Figure 1) belonging to ticks, lice and mange mites were found infesting cattle and sheep in the study area. The major identified genera of ticks were Boophilus, Amblyomma, Rhepicephalus and Hyalomma. Damalina and Linognathus, Demodex and Psoroptes were responsible for pediculosis and mange mite infestations, respectively. Out of 202 cattle 
examined for ectoparasites, 95 were found to be infested with one or more ectoparasites with the overall prevalence of $47.0 \%$ (95\% CI: 40.1-53.9), and of the 182 examined sheep, 73 were harbored one or more ectoparasites with the overall prevalence of $40.1 \%$ (95\% CI: $32.9-47.3)$.

\subsection{Prevalence and Risk Factors of Tick Infestation}

Of the 384 examined animals, $120(31.3 \%)$ (95\% CI: 26.6-35.9) were harbored one or more tick genera. Of the 202 cattle and 182 sheep examined, 71 (35.2\%) and 49
$(26.9 \%)$ were infested with one or more genera of ticks, respectively. Female animals were two times at risk to be infested with ticks than males in cattle $(\mathrm{OR}=2.16 ; 95 \% \mathrm{CI}$ : 1.1-4.2) and sheep (OR=2.2; 95\% CI: 1.1-4.4). Moreover, cattle and sheep managed under extensive production system were $12(\mathrm{OR}=12.1 ; 95 \% \mathrm{CI}: 4.2-35.2)$ and 6 $(\mathrm{OR}=6.1 ; 95 \% \mathrm{CI}: 1.8-20.9)$ times at risk to be infested with ticks than that of cattle and sheep kept under intensive type of production, respectively (Table 1 ).

Table 1. Association and univariate analysis of different risk factors with tick infestation in cattle and sheep examined in and around Bishoftu town, Ethiopia

\begin{tabular}{|c|c|c|c|c|c|c|c|c|}
\hline \multirow{3}{*}{ Variable } & \multicolumn{8}{|c|}{ Species } \\
\hline & \multicolumn{4}{|c|}{ Bovine $(n=202)$} & \multicolumn{4}{|c|}{ Ovine (n=182) } \\
\hline & Total & Positive (\%) & $\chi 2$ (P-value) & OR(95\% CI) & Total & Positive (\%) & $\chi 2$ (P-value) & OR(95\% CI) \\
\hline Sex & & & $5.4(0.020)$ & & & & $5.5(0.019)$ & \\
\hline Male & 153 & $47(30.7)$ & & 1 & 89 & $18(20.2)$ & & 1 \\
\hline Female & 49 & $24(48.9)$ & & $2.2(1.1-4.2)$ & 93 & $31(33.3)$ & & $2.2(1.1-4.4)$ \\
\hline Age & & & $0.007(0.93)$ & & & & $2.8(0.092)$ & \\
\hline Young & 42 & $15(35.7)$ & & 1 & 46 & $8(17.4)$ & & 1 \\
\hline Adult & 160 & $56(35.0)$ & & $0.9(0.5-2.0)$ & 136 & $41(30.15)$ & & $2.1(0.8-4.8)$ \\
\hline Body condition & & & $1.1(0.58)$ & & & & $1.15(0.28)$ & \\
\hline Good & 84 & $29(34.5)$ & & 1 & 101 & $24(23.8)$ & & 1 \\
\hline Medium & 80 & $26(32.5)$ & & $0.9(0.5-1.8)$ & - & - & & - \\
\hline Poor & 38 & $16(35.1)$ & & $1.4(0.6-3.0)$ & 81 & $25(30.9)$ & & $0.7(0.4-1.4)$ \\
\hline Breed & & & $1.2(0.27)$ & & & & & \\
\hline Local & 170 & $57(33.5)$ & & 1 & - & - & - & - \\
\hline Cross & 32 & $14(43.7)$ & & $1.5(0.7-3.3)$ & - & - & - & - \\
\hline Production system & & & $29.4(0.000)$ & & & & $10.3(0.001)$ & \\
\hline Intensive & 59 & $4(6.8)$ & & 1 & 41 & $3(7.3)$ & & 1 \\
\hline Extensive & 143 & $67(46.8)$ & & $12.1(4.2-35.2)$ & 141 & $46(32.6)$ & & $6.1(1.8-20.9)$ \\
\hline
\end{tabular}

\subsection{Prevalence and Risk Factors of Pediculosis}

Table 2. Association and univariate analysis of different risk factors with prevalence of pediculosis in cattle and sheep examined at Bishoftu town, Ethiopia

\begin{tabular}{|c|c|c|c|c|c|c|c|c|}
\hline \multirow{3}{*}{ Variable } & \multicolumn{8}{|c|}{ Species } \\
\hline & \multicolumn{4}{|c|}{ Bovine $(n=202)$} & \multicolumn{4}{|c|}{ Ovine $(n=182)$} \\
\hline & Total & Positive (\%) & $\chi 2$ (P-value) & OR(95\% CI) & Total & Positive (\%) & $\chi 2$ (P-value) & OR(95\% CI) \\
\hline Sex & & & $19.3(0.000)$ & & & & $0.6(0.434)$ & \\
\hline Male & 153 & $6(3.9)$ & & 1 & 89 & $13(14.6)$ & & 1 \\
\hline Female & 49 & $12(24.5)$ & & $7.9(2.8-22.6)$ & 93 & $10(10.7)$ & & $0.70(0.3-1.7)$ \\
\hline Age & & & $0.03(0.876)$ & & & & $0.4(0.542)$ & \\
\hline Young & 42 & $4(9.5)$ & & 1 & 46 & $7(15.2)$ & & 1 \\
\hline Adult & 160 & $14(8.8)$ & & $0.9(0.3-2.9)$ & 136 & $16(11.8)$ & & $0.7(0.3-1.9)$ \\
\hline Body condition & & & $2.3(0.317)$ & & & & $0.1(0.732)$ & \\
\hline Good & 84 & $9(10.7)$ & & 1 & 101 & 12(11.9) & & 1 \\
\hline Medium & 80 & $8(10.0)$ & & $0.9(0.3-2.5)$ & - & - & & - \\
\hline Poor & 38 & $1(2.6)$ & & $0.2(0.02-1.8)$ & 81 & 11(13.6) & & $0.9(0.4-2.1)$ \\
\hline Breed & & & $4.6(0.033)$ & & & & & \\
\hline Local & 170 & $12(7.1)$ & & 1 & - & - & - & - \\
\hline Cross & 32 & $6(18.7)$ & & $3.0(1.1-8.8)$ & - & - & - & - \\
\hline Production system & & & $5.5(0.020)$ & & & & $6.4(0.040)$ & \\
\hline Intensive & 59 & $2(3.4)$ & & 1 & 41 & $3(7.3)$ & & 1 \\
\hline Extensive & 143 & $16(11.2)$ & & $3.6(1.8-8.1)$ & 141 & $20(14.2)$ & & $2.1(1.6-4.4)$ \\
\hline
\end{tabular}

Of the 384 examined animals, 41 were found infested with one or more lice with the prevalence of $11.0 \%(95 \%$ CI: 2.7-17.3). The prevalence of pediculosis was $8.9 \%$ and $12.6 \%$ in bovine and ovine, respectively. The prevalence of pediculosis in cattle was significantly varied among sex $(\chi 2=19.3 ; \mathrm{P}=0.000)$ and breed $(\chi 2=4.5 ; \mathrm{P}=0.033)$, thus female $(\mathrm{OR}=7.9 ; 95 \%$ CI: 2.8-22.6) and cross breed $(\mathrm{OR}=3.0 ; 95 \% \mathrm{CI}: 1.1-8.8)$ cattle were more at risk than male and indigenous local cattle breeds for pediculosis, respectively (Table 2). Moreover, production system was also found significantly associated with the prevalence of pediculosis in cattle $(\chi 2=5.5 ; \mathrm{P}=0.020)$ and sheep $(\chi 2=6.6$; 
$\mathrm{P}=0.04)$; therefore, cattle $(\mathrm{OR}=3.6 ; 95 \% \mathrm{CI}: 1.8-8.1)$ and sheep (OR=2.1: 95\% CI: 1.6-4.4) managed under extensive management system were being more at risk to be infested with lice than cattle and sheep managed under intensive management (Table 2).

\subsection{Prevalence and Risk Factors of Mange Mite Infestation}

Of the 384 examined animals for ectoparasites, 17 were infested with mange mites with a prevalence of $4.4 \%(95 \%$ CI: 1.72- 7.9). The prevalence of demodicosis and psoroptic mange in cattle was $6.6 \%$ and $0.6 \%$, respectively.
However, the only mange mite species encountered in sheep was Psoroptes with prevalence rate of $2.2 \%$. As shown in table 3 , age in cattle $(\chi 2=14.0 ; \mathrm{P}=0.000)$ and in sheep $(\chi 2=3.8 ; \mathrm{P}=0.040)$ and body condition in cattle $(\chi 2=7.7 ; \mathrm{P}=0.021)$ were found statistically significant with the prevalence of mange mite infestation. Therefore, young cattle $(\mathrm{OR}=7.3 ; 95 \% \mathrm{CI}: 2.2-23.7)$ and sheep $(\mathrm{OR}=4.7 ; 95 \%$ CI: 1.7-8.9) were more susceptible to mange mite infestation than adult cattle and sheep, respectively. Similarly, poor body conditioned cattle were found 4 times $(\mathrm{OR}=4.0 ; 95 \% \mathrm{CI}: 1.3-12.5)$ more likely to be infested with mange mite than good body conditioned cattle.

Table 3. Association and univariate analysis of different risk factors with prevalence of mange mite infestation in cattle and sheep examined at Bishoftu town, Ethiopia

\begin{tabular}{|c|c|c|c|c|c|c|c|c|}
\hline \multirow{3}{*}{ Variable } & \multicolumn{8}{|c|}{ Species } \\
\hline & \multicolumn{4}{|c|}{ Bovine $(n=202)$} & \multicolumn{4}{|c|}{ Ovine $(n=182)$} \\
\hline & Total & Positive (\%) & $\chi 2$ (P-value) & OR(95\% CI) & Total & Positive (\%) & $\chi^{2}$ (P-value) & OR(95\% CI) \\
\hline Sex & & & $0.3(0.571)$ & & & & $0.2(0.686)$ & \\
\hline Male & 153 & $9(5.9)$ & & 1 & 89 & $2(2.3)$ & & 1 \\
\hline Female & 49 & $4(8.2)$ & & $1.4(0.4-4.8)$ & 93 & $3(3.2)$ & & $1.45(0.2-8.9)$ \\
\hline Age & & & $14.0(0.000)$ & & & & $3.8(0.040)$ & \\
\hline Young & 42 & $8(19.1)$ & & $7.3(2.2-23.7)$ & 46 & $3(6.5)$ & & $4.7(1.7-8.9)$ \\
\hline Adult & 160 & $5(3.1)$ & & 1 & 136 & $2(1.5)$ & & 1 \\
\hline Body condition & & & $7.7(0.021)$ & & & & $2.6(0.105)$ & \\
\hline Good & 84 & $0(0.0)$ & & 1 & 101 & $1(0.1)$ & & 1 \\
\hline Medium & 80 & $3(3.8)$ & & $1.2(0.2-1.8)$ & - & - & & - \\
\hline Poor & 38 & $10(26.3)$ & & $4(1.3-12.5)$ & 81 & $4(4.9)$ & & $0.2(0.02-1.7)$ \\
\hline Breed & & & $2.3(0.128)$ & & & & & \\
\hline Local & 170 & $9(5.3)$ & & 1 & - & - & - & - \\
\hline Cross & 32 & $4(12.5)$ & & $2.6(0.7-8.8)$ & - & - & - & - \\
\hline Production system & & & $0.3(0.615)$ & & & & $0.9(0.343)$ & \\
\hline Intensive & 59 & $3(5.1)$ & & 1 & 41 & $2(4.9)$ & & 1 \\
\hline Extensive & 143 & $10(7.0)$ & & $1.4(0.4-5.3)$ & 141 & $3(2.1)$ & & $0.4(0.1-2.6)$ \\
\hline
\end{tabular}

\section{Discussion}

The present study revealed that skin diseases caused by ectoparasites were common in and around Bishoftu town in cattle and sheep. The overall prevalence of ectoparasites in cattle was $47.0 \%$, which was slightly higher than the findings reported by other authors from different regions of Ethiopia: $40.2 \%$ [19], 15.41\% [18] and 27.3\% [7]. However, this result was lower than the prevalences, $73.3 \%, 65.5 \%$ and $64.07 \%$ reported by Tadesse et al. [29] from Ethiopia, and Islam et al. [30] and Rony et al. [31] from Bangladesh, respectively.

On the other hand, in the present study, $40.1 \%$ sheep were infested with one or more ectoparasites, which was comparable with the reports of Zeryehun and Atomsa [32], and Amare, et al. [33] who reported $43.9 \%$ and $44.9 \%$ in sheep respectively. However, the present result was lower than the prevalence reported by different authors from other regions of Ethiopia: 55.7\% [34], 81.5\% [20], 99.38\% [35], $51.7 \%$ [13] and $78.4 \%$ [15]. Variation in geographical locations, climatic conditions, and management practices in the different study areas might have contributed for the disparity in prevalence.

In the present study, the identified genera of ticks in cattle and sheep were Boophilus, Amblyomma,
Rhepicephalus and Hyalomma. Of these, higher proportion of Amblyomma (67.6\%) and Boophilus (32.4\%) were observed in cattle. Similarly, higher proportion of Amblyomma (48.98\%) and Rhipicephalus (46.97\%) were identified in sheep. Moreover, two genera of lice; Linognathus and Damalina were identified in cattle and sheep, and also Demodex (in both cattle and sheep) and Psoroptes (in sheep only) were the identified genera of mites in the study area. Similar genera of ticks, lice and mites were identified in different location of the country by different authors [18, 32,34,36,37].

In this study, ticks were found to be the most prevalent ectoparasites in cattle with a prevalence of $35.2 \%$. This finding was in a general agreement with the reports of Yacob et al. [18,19] and Onu et al. [7] who reported higher prevalence of tick infestation than other ectoparasites from different regions of the country. Moreover, ticks were the most prevalent ectoparasites in sheep of the study area which is consistent with the previous findings [13,34,37]. In contrast to the present study, higher prevalence of lice infestation was recorded in sheep in different parts of the country $[15,18,19,32,33]$. These variations could arise from the management and ectoparasite control practices differences in the different study areas.

In this study, it was observed that the prevalence of tick 
and lice infestation in both cattle and sheep was higher in extensive production system than intensive production. It is similar to the findings of Rony et al. [31] and Abebe et al. [13] who reported the highest ectoparasitic infestation in extensive farming system. Moreover, the higher tick infestation in female cattle of the present study was in line with the report of Rony et al. [31]. Studies have indicated that the occurrence and spread of skin diseases have been shown to correlate with host factors, poor management, climatic factors, feed scarcity and inadequate veterinary services [18,19, 32,34,36].

\section{Conclusion}

The present study revealed that widespread occurrence of ectoparasites in cattle and sheep in the study area, and the major ectoparasites identified were tick, lice and mange mite, thus, improved management practice and wellcoordinated control interventions are required.

\section{Acknowledgement}

The authors would like to thank the school of veterinary medicine of Addis Ababa University for supporting this research.

\section{References}

[1] Ayele, S., Assegid, W., Jabbar, M., Ahmed, M. and Belachew, H. (2003). Livestock marketing in Ethiopia. A review of structure performance and development initiatives socio-economic and policy research working papers. ILRI, Nairobi, Kenya, Pp: 35.

[2] Bansal, G. C. (2005). Bovine theileriosis in India: an overview. Proceedings of National Academy of Science, India, 75: 134-43.

[3] Kassa, B. (1998). Control of Sheep and Goat Skin Diseases. In: By Ian, B.C. and Bayou, B. (eds.) Proceedings of Control of Sheep and Goat Skin Diseases for Improved Quality of Hides and Skin, 13-14 Feb, 1998, FAO, Addis Ababa.

[4] Wondwossen, A. (2000). Sheep and goat skin disease control initiatives in Amhara region Ethiopia. Veterinary epidemiology news letter, pp: 1-9.

[5] Bekele, T. (2002). Studies on seasonal dynamics of ticks of Ogaden cattle and individual variation in resistance to ticks in eastern Ethiopia. Journal of Veterinary Medicine, 49: 285-288.

[6] Wall, R. (2007). Ectoparasites: Future challenges in a changing world. Veterinary Parasitology, 148: 62-74.

[7] Onu, S.H., and Shiferaw, T.Z. (2013). Prevalence of ectoparasite infestations of cattle in Bench Maji zone, southwest Ethiopia, Veterinary World, 6: 291-294.

[8] Byford, R. L., Craig, M. E. and Crosby, B. L. (1992). A review of ectoparasites and their effect on cattle production. Journal of Animal Science, 70: 597-602.
[9] Kusilika, L. and Kambarage, D.(1996). Common diseases of sheep and goat in Sub saharan Africa.Vetaid center for Veterinary medicine, Scotland, 102-109.

[10] Heath, C.G. (1994). Ectoparasites of livestock in New Zealand. New Zealand Journal of Zoology, 21: 23-38.

[11] Holds worth, P.A. (2005). ectoparasiticide use in contemporary Australian livestock production. Avacre, Canberra Australia, pp: 58-69.

[12] Regassa, A. (2001). Tick infestation of Borana cattle in the Borana Province of Ethiopia. Onderstepoort, Journal of Veterinary Research, 68: 41-45.

[13] Abebe, R., Tatek, M. Megersa, B. and Sheferaw, D. (2011) Prevalence of Small Ruminant Ectoparasites and Associated Risk Factors in Selected Districts of Tigray Region, Ethiopia. Global Veterinaria, 7: 433-437.

[14] Tikit, B. and Addis, M. (2011). Distribution of Ixodid Ticks on Cattle in and Around Holeta Town, Ethiopia. Global Veterinaria, 7: 527-531.

[15] Fentahun, T., Woldemariam, F. Chanie, M. and Berhan, M. (2012). Prevalence of Ectoparasites on Small Ruminants in and Around Gondar Town. American-Eurasian Journal of Scientific Research, 7: 106-111.

[16] Kebede, M.C. (2013). Effect of Small Ruminant Ectoparasites in the Tanning Industry in Ethiopia: A review. Journal of Animal science advances, 3: 424-430.

[17] Radostits, O.M., Gay, C. Hinchcliff, K.W. and Constable, P.D. (2007). A textbook of the diseases of cattle, sheep, goats, pigs and horses, 10 edition, Suanders, Edinburgh, London, pp: 1585-1612.

[18] Yacob, H., Nesanet, B.and Dinka, A. (2008a). Part II: Prevalences of major skin diseases in cattle, sheep and goats at Adama Veterinary Clinic, Oromia regional state, Ethiopia. Revue de Médecine Vétérinaire, 159: 455-461.

[19] Yacob, H., Ataklty, H. and Kumsa, B. (2008b). Major ectoparasites of cattle in and around Mekelle, northern Ethiopia. Entemological Research, 38: 126-130.

[20] Chanie, M., Negash, T. and Sirak, A. (2010). Ectoparasites are the major causes of various types of skin lesions in small ruminants in Ethiopia. Tropical Animal Health and Production, 42: 1103-1109.

[21] Yacob, H.T. (2014). Ectoparasitism: Threat to Ethiopian small ruminant population and tanning industry. Journal of Veterinary Medicine and Animal Health, 6: 25-33.

[22] NMSA, (2004). National Meteorology Serves Agency, Addis Ababa, Ethiopia.

[23] Thrusfield, M. (2005). Veterinary Epidemiology, $3^{\text {rd }}$ ed., Blackwell Science Ltd., Edinburgh, UK., Pp: 228-247.

[24] Aiello S. and Mays, A. (1998). The Merck veterinary manual, $8^{\text {th }}$ ed., Merck and Co, Inc, White house station, NJ. USA, Pp: 131-133.

[25] Nicholson, M.J. and Butterworth, M.A. (1986). A guide to condition scoring zebu cattle. International livestock center for Africa (ILCA). Addis Ababa, Ethiopia, Pp: 72-74.

[26] Gatenby, R.M. (2002). Sheep: the Tropical Agriculturalist. $2^{\text {nd }}$ Ed., Macmillan Publishers Ltd., CTA, Wageningen, London, $\mathrm{Pp}: 178$. 
[27] Soulsby, E. (1982). Helminths, Arthropods and protozoa of Domesticated Animals, 7th ed., Baillere Tindall, London, pp: 492-552.

[28] Urquhart, G.M., Armour, J. Duncan, J.L. Dunn, A.M. and Jennings, F.W. (1996). Veterinary Parasitology, $2^{\text {nd }}$ ed., Chandler, E.A., Gaskell, C.J. and Gaskell, R.M. (eds), Black well science Ltd., UK., pp. 180-201.

[29] Tadesse, A., Fentaw, E. Mekbib, B. Abebe, R. Mekuria, S. and Zewdu, E. (2011). Study on the prevalence of ectoparasite infestation of ruminants in and around Kombolcha and damage to fresh goat pelts and wet blue (pickled) skin at Kombolch Tannary, Northestern Ethiopia. Ethiop. Veterinary Journal, 15: 87-101.

[30] Islam, M.S., Rahman, S.A. Sarker, P. and Anisuzzaman, M.M.H. (2009). Prevalence and population density of ectoparasitic infestation in cattle in Sirajgonj district, Bangladesh. Bangladish Research Publications Journal, 2: 332-339.

[31] Rony, S.A., Mondal, M.M.H. Begum, N. Islam, M.A. and Affroze, S. (2010). Epidemiology of ectoparasitic infestations in cattle at bhawal Forest area, gazipur. Bangladish Journal of Veterinary Medecine, 8: 27 - 33.
[32] Zeryehun, T. and Atomsa, M. (2012). Ectoparasite infestations of sheep and goats. Eurasian Journal of Veterinary Science, 28: 185-189.

[33] Amare, S., Asfaw, Y. and Yacob, H. (2013). Ectoparasites of Sheep and Goats in North-West Amhara Regional State, Ethiopia. Ethiopian Veterinary Journal, 17:55-67.

[34] Yacob, H., Yalew, T. and Dinka, A. (2008c). Part I: Ectoparasite prevalences in sheep, and goats in and around Wolaita Soddo, Southern Ethiopia. Revue de Médecine Vétérinaire, 159: 450-454.

[35] Bekele, J., Tariku, M. and Abebe, R. (2011). External parasite infestations in sheep and goats in Wolmera district of Oromia region, central Ethiopia. Journal of Animal Veterinary Advance, 10: 518-523.

[36] Kumsa, B., Beyecha, K. and Geloye, M. (2012). 'Ectoparasites of sheep in three agro-ecological zones in central Oromia, Ethiopia', Onderstepoort, Journal of Veterinary Research, 79: 442.

[37] Tesfaye, D., Assefa, M. Demissie, T. and Taye, M. (2012). Ectoparasites of small ruminants presented at Bahir Dar Veterinary Clinic, Northwest Ethiopia. African Journal of Agricultural Research, 7: 4669-4674. 